Оригинальная статья/Original article

УДК 678.5: 504.064 .45

DOI: http://doi.org/10.20914/2310-1202-2018-4-356-360

Оценка эффективности иммобилизации активного ила

на композитных материалах «полиэтилен:полисахариды»

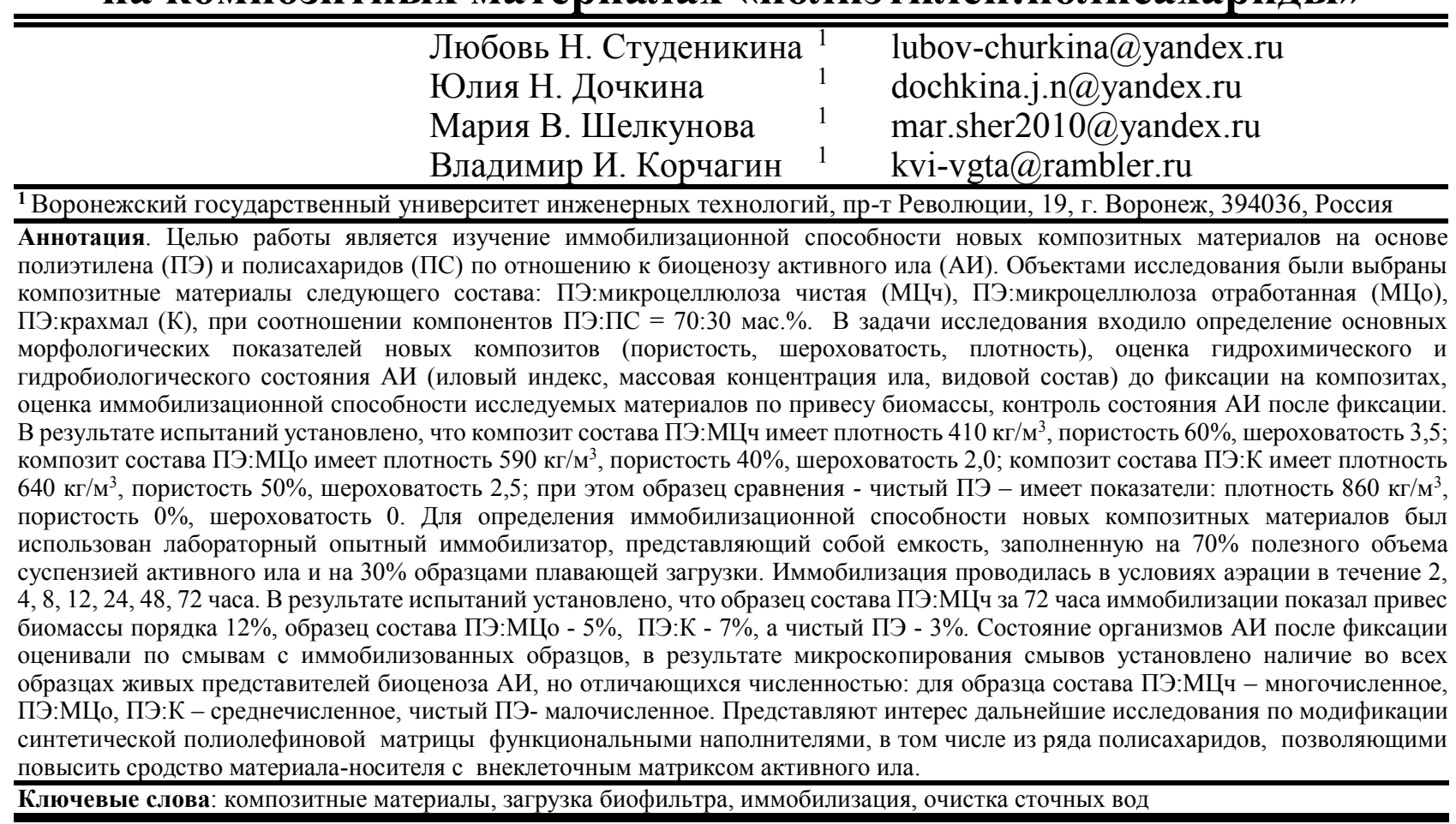

\title{
Evaluation of the effectiveness of immobilization of activated sludge on composite materials "polyethylene:polysaccharides"
}

\begin{tabular}{lll}
\hline \hline Lubov N. Studenikina & 1 & lubov-churkina@yandex.ru \\
Julia N. Dochkina & 1 & dochkina.j.n@yandex.ru \\
Mariya V. Shelkunova & 1 & mar.sher2010@yandex.ru \\
Vladimir I. Korchagin & 1 & kvi-vgta@rambler.ru \\
\hline
\end{tabular}

${ }^{1}$ Voronezh state university of engineering technologies, Revolution Av., 19 Voronezh, 394036, Russia

Abstract.The aim of this work is to study the immobilization ability of new composite materials based on polyethylene (PE) and polysaccharides (PS) in relation to the biocenosis of activated sludge (AS). The objects of the study were selected composite materials of the following composition: PE : pure microcellulose (MCc), PE : waste microcellulose (MCw), PE : starch (ST), at a ratio of components PE : PS $=70: 30$ wt.\%. The objectives of the study were to determine the main morphological parameters of new composites (porosity, roughness, density), assessment of hydrochemical and hydrobiological state of AS (silt index, mass concentration of silt, species composition) until it locks into composites, assessment of the immobilization ability of the studied materials by biomass weight gain, monitoring of the state of AS after fixing. The tests found that the composite of structure of PE : MCc of has a density of $410 \mathrm{~kg} / \mathrm{m}^{3}$ and a porosity of $60 \%$, the roughness of 3.5 ; the composite of structure of PE: MCw has a density of $590 \mathrm{~kg} / \mathrm{m}^{3}$ and a porosity of $40 \%$, roughness of 2.0 , composite of structure of PE : ST has a density of $640 \mathrm{~kg} / \mathrm{m}^{3}$ and a porosity of $50 \%$, the roughness of 2.5 ; wherein the reference sample - PE - has the parameters: density $860 \mathrm{~kg} / \mathrm{m}^{3}$ and a porosity of $0 \%$, roughness 0 . To determine the immobilization capacity of the new composite materials, a laboratory experimental immobilizer was used, which is a container filled with $70 \%$ of the useful volume of the active sludge suspension and $30 \%$ of the floating loading samples. Immobilization was carried out under aeration conditions during $2,4,8,12,24,48,72$ hours. As a result of tests it is established that the sample of structure of PE : MCc for 72 hours of immobilization showed a gain of biomass of the order of $12 \%$, the sample of structure of $\mathrm{PE}: \mathrm{MCW}-5 \%$, the sample of structure of PE : $\mathrm{ST}-7 \%, \mathrm{PE}-3 \%$. The condition of the organisms AS after fixing was evaluated by washings with immobilized samples, as a result of microscopy of washouts, the presence of living representatives of the biocenosis of AS in all samples was established, but they differ in number: for the sample of structure of PE : MCc - numerous, PE : MCw, PE : ST - average number, PE - small number. Further studies on the modification of the synthetic polyolefin matrix by functional fillers, including those from a number of polysaccharides, are of interest, allowing to increase the affinity of the carrier material with the extracellular matrix of activated sludge.

Keywords:composite material, loading the biofilter, immobilization, biological wastewater treatment

Для цитирования Студеникина Л.Н.., Дочкина Ю.Н., Шелкунова М.В.,
Корчагин В.И. Оценка эффективности иммобилизации активного ила на композитных материалах «полиэтилен:полисахариды»
/Вестник ВГУИТ. 2018. Т. 80. № 4. С. 356-360. doi:10.20914/23101202-2018-4-356-360
For citation

Studenikina L.N., Dochkina Ju.N., Shelkunova M.V., Korchagin V.I. Evaluation of the effectiveness of immobilization of activated sludge on composite materials "polyethylene:polysaccharides". Vestnik VGUIT [Proceedings of VSUET]. 2018. vol. 80. no. 4. pp. 356-360. (in Russian). doi:10.20914/2310-1202-2018-4-356-360 


\section{Введение}

В связи с непрерывно возрастающим антропогенным воздействием на окружающую среду количество загрязняющих веществ, поступающих в природные объекты, постоянно увеличивается. Основными источниками крупномасштабного поступления ксенобиотиков в водные компоненты биосферы являются сбросы производственных и хозяйственно-бытовых сточных вод. Одним из самых распространенных способов удаления из сточных вод загрязнителей является биохимическая очистка с помощью активного ила (АИ).

Традиционно применяемые установки биологической очистки сточных вод предусматривают обработку стоков суспензией АИ (свободноплавающим илом). Такой способ малоэффективен при постоянно возрастающей нагрузке на очистные сооружения, а также влечет за собой необходимость утилизации большого количества избыточного АИ, образование которого вынуждает природопользователя проводить тщательную доочистку биологически очищенных сточных вод перед их сбросом или дальнейшей обработкой.

В ходе реконструкции станций очистных сооружений все чаще встречается применение на стадии биологической очистки плавающей в кипящем слое загрузки с целью иммобилизации (фиксации) на ней организмов АИ, что приводит к повышению эффективности очистки и снижению количества осадка избыточного ила. Однако материалы, используемые для производства носителей биомассы, имеют ряд недостатков: низкая адсорбционная способность, дороговизна, недолговечность, повышенные эксплуатационные требования, которые неизбежно влекут за собой дополнительные эксплуатационные затраты, а по истечении короткого промежутка времени снижение эффективности очистки.

В качестве носителя биомассы возможно использование керамзита, кварцевого песка, активированного угля, полиэтилена и полипропилена и пр. При этом гранулированный вид материалов-носителей, имеющих плотность меньше плотности сточных вод, позволяет обеспечить создание кипящего слоя, что приводит к увеличению площади контакта между микроорганизмами-деструкторами и загрязнителями [1].

В последнее время все больше внимания уделяется разработке способов повышения иммобилизационной способности биологических загрузок путем изменения их геометрической формы, структуры и состава. Так, например, наполнение полиэтиленовой матрицы микроцеллюлозой позволяет увеличить биологическую адсорбционную емкость материала до 30\% [2].
В исследованиях [3-6] обосновано внедрение «ершей» и волокнисто-пористых носителей в аэротенки, что позволяет повысить концентрацию биомассы, снизить ее вымываемость из биологических очистных сооружений, не оказывая влияния на видовой состав биоценоза АИ. В работе [7] в качестве носителей микрофлоры предлагается использовать полиамидные волокнистые материалы (нейлон), что позволит создать альтернативу полиэтилену и полипропилену, повысить концентрацию ила в аэротенках относительно свободноплавающего биоценоза, проводить воздушную регенерацию носителей. В работе [8] изучено использование сетчатых капроновых носителей биомассы и установлено, что сетчатый вид позволяет организмам АИ внедриться непосредственно в структуру носителя, однако автор отмечает, что инертность капронового материала приводит к обеднению видового состава АИ, снижению численности микроорганизмов, прекращению роста в случае недостатка питательных веществ в биореакторе.

Разработка и внедрение новых материалов, обладающих иммобилизационной способностью, является перспективным направлением не только в очистке сточных вод, но и в обезвреживании газовых выбросов. Основными задачами при этом являются снижение стоимости носителей биомассы за счет использования вторичных сырьевых ресурсов и отходов различного производства (например, углеродсодержащих отходов - карбонизатов [9]), а также повышение эффективности очистки выбросов, так, например, установлено, что минеральные носители биомассы из фосфогипсов повышают эффективность обессеривания выбросов теплоэлектростанций [10].

В зарубежных исследованиях, направленных на повышение качества работы сооружений искусственной биологической очистки сточных вод, также прослеживается тенденция к использованию материалов с повышенными иммобилизационными свойствами [11].

Цель работы - установление влияния морфологических характеристик композиции «полиэтилен (ПЭ): полисахарид (ПС)» на эффективность иммобилизации микрофлоры АИ.

В задачи исследования входило определение основных морфологических показателей новых композитов (пористость, шероховатость, плотность), оценка гидрохимического и гидробиологического состояния АИ (иловый индекс, массовая концентрация ила, видовой состав) до фиксации на композитах, оценка иммобилизационной способности исследуемых материалов по привесу биомассы, контроль состояния АИ после фиксации. 


\section{Материалы и методы}

Объектами исследования были выбраны новые композитные материалы следующего состава: ПЭ:микроцеллюлоза чистая (МЦч), ПЭ:микроцеллюлоза отработанная (МЦо), ПЭ:крахмал (К), при соотношении компонентов ПЭ:ПС = 70:30 мас.\%. Отработанная микроцеллюлоза - отход производства растительных масел, содержащий в составе жирные кислоты, воск и др. [2]. В качестве образца для сравнения был выбран чистый полиэтилен, из которого в настоящее время производится большинство представленных на рынке загрузок для биологической очистки сточных вод.

Морфологические свойства изучаемых материалов были определены в соответствии с утвержденными методиками. Плотность композитов определяли по ГОСТ 15139-69. Шероховатость поверхности оценивали по отношению максимальной и минимальной толщины образца с учетом ГОСТ 2789-73. Определение пористости проводили по стандартной методике расчета через массы образца в насыщенном водой и сухом состоянии. Гидрохимические показатели проб АИ определяли согласно «Методике определения массовой концентрации активного ила» ФР 1.31.2008.04397. Видовое разнообразие организмов АИ было определено электронным микроскопированием с использованием «Рекомендаций по проведению гидробиологического контроля на сооружениях биологической очистки», «Атласа Академии наук СССР «Фауна аэротенков», «Краткого определителя водных беспозвоночных животных». Прирост биомассы АИ определяли весовым методом с использованием аналитических весов.

\section{Результаты и обсуждение}

Результаты оценки морфологических свойств новых композитов представлены в таблице 1.

Морфологические характеристики новых композитных материалов

Таблица 1.

Morphological characteristics of the new composite materials

\begin{tabular}{|c|c|c|c|c|}
\hline Показатель | Indicator & $\begin{array}{c}\text { ПЭ: МЦч } \\
\text { РЕ : MCc }\end{array}$ & $\begin{array}{c}\text { ПЭ: МЦо } \\
\text { PE : MCw }\end{array}$ & $\begin{array}{c}\text { ПЭ: К } \\
\text { PE : ST }\end{array}$ & $\begin{array}{c}\text { ПЭ } \\
\text { PE }\end{array}$ \\
\hline Пористость, \% (Porosity, \%) & 60 & 40 & 50 & 0,0 \\
\hline Шероховатость поверхности (Surface roughness) & 3,5 & 2,0 & 2,5 & 0,0 \\
\hline Плотность, кг $/ \mathrm{M}^{3}$ (Density, $\mathrm{kg} / \mathrm{m}^{3}$ ) & 410 & 590 & 640 & 860 \\
\hline
\end{tabular}

Важнейшим условием получения достоверных результатов исследования эффективности иммобилизации АИ на новых композитных материалах является использование качественной биомассы. В работе использовали АИ, имеющий иловый индекс $95 \mathrm{~cm}^{3} / 1$ г ила и массовую концентрацию 5,2 г/дм ${ }^{3}$. В результате гидробиологического анализа было установлено, что АИ визуализируется как хорошо сформированный плотный хлопок бактериальной слизи. Видовое разнообразие АИ представлено основными укрупненными группами таких организмов, как прикрепленные инфузории, коловратки, тихоходки, нематоды, раковинные амебы, нитчатые бактерии и др. Результаты гидробиологического контроля АИ согласуются с известными данными [12].

Для определения иммобилизационной способности новых композитных материалов был использован лабораторный опытный иммобилизатор, представляющий собой емкость, заполненную на 70 \% полезного объема суспензией АИ и на $30 \%$ образцами плавающей загрузки. Иммобилизация проводилась в условиях аэрации в течение $2,4,8,12,24,48,72$ ч. Оценка эффективности иммобилизации проводилась сравнением привеса после высушивания до постоянной массы образца с иммобилизованной биомассой. Высушивание иммобилизованных образцов проводилось в сушильном шкафу при температуре $50^{\circ} \mathrm{C}$ в течение 120 мин. Результаты эффективности проведенной иммобилизации на исследуемых материалах представлены на рисунке 1.

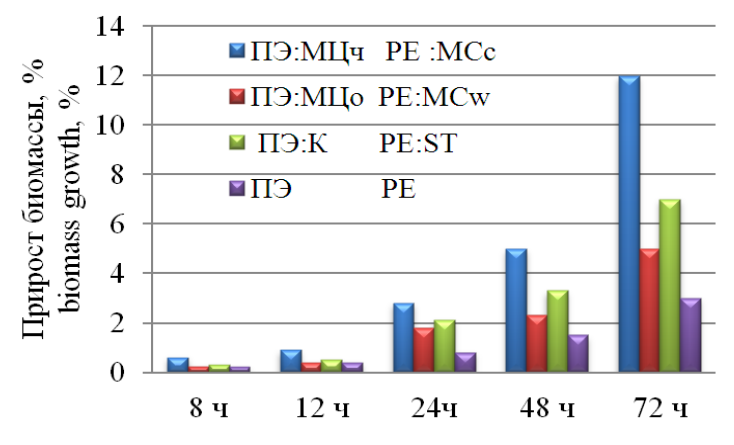

Продолжительность иммобилизаци, часы immobilization time, hour

Рисунок 1. Оценка эффективности иммобилизации АИ на композитных материалах

Figure 1. Evaluation of the effectiveness of immobilization of activated sludge on composite materials 


\section{Becmник BTYYMTI/Proceedings of VSVET, TIT. 80, № 4, 2018}

Следует отметить, что при продолжительности иммобилизации менее 8 ч не наблюдалось привеса биомассы у всех исследуемых образцов.

Не менее важным показателем эффективности иммобилизации АИ является оценка состояния организмов после фиксации. Для того чтобы осуществить оценку уже иммобилизованных микроорганизмов техникой микроскопирования, были сделаны смывы дистиллированной водой с каждого вида загрузки. В смывной воде с плавающей загрузки из композитного
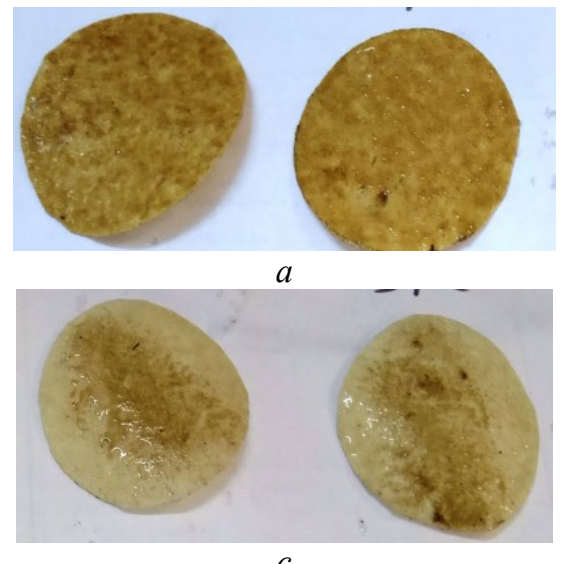

$c$ материала ПЭ: МЦч отмечено значительное количество живых подвижных микроорганизмов, отчетливо видна микробная слизь. Смывы с плавающей загрузки состава ПЭ:МЦо и ПЭ:К характеризуются среднечисленным содержанием живых подвижных микроорганизмов, незначительным количеством микробной слизи. В смыве образца из чистого ПЭ обнаружены единичные представители биоценоза.

Новые композитные материалы с иммобилизованным биоценозом представлены на рисунке 2.
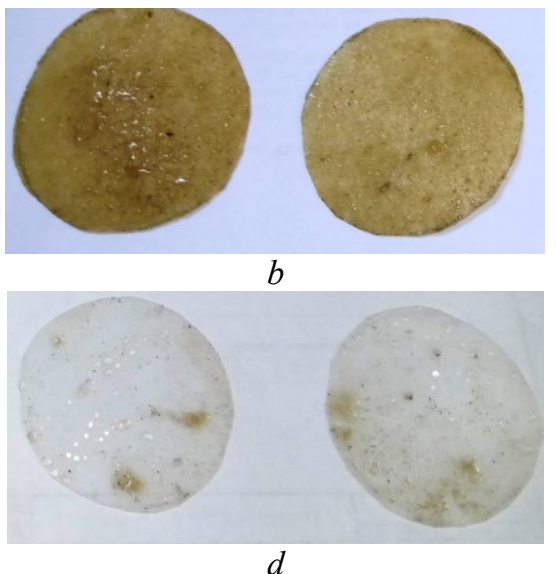

Рисунок 2. Образцы композитных материалов с иммобилизованным биоценозом: $a-$ ПЭ:МЦч; $b-$ ПЭ:МЦо; $c-\Pi Э: \mathrm{K} ; \mathrm{d}-\Pi Э$

Figure 2. Samples of composite materials with immobilized biocenosis: $a-\mathrm{PE}: \mathrm{MCc} ; b-\mathrm{PE}: \mathrm{MCw} ; c-\mathrm{PE}: \mathrm{ST} ; \mathrm{d}-\mathrm{PE}$

\section{Заключение}

На основании анализа полученных данных об эффективности иммобилизации биоценоза АИ можно утверждать, что наилучшие результаты показывает композитный материал ПЭ:МЦч, что обусловлено высокоразвитой структурой материала, шероховатостью поверхности, наличием гидрофильного наполнителя.

\section{ЛИТЕРАТУРА}

1 Корчевская Ю.В., Кадысева А.А., Горелкина Г.А., Маджугина А.А. и др. Применение псевдоожиженного слоя в биологической очистке сточных вод // Вестник Алтайского государственного аграрного университета. 2016. № 2. C. 67-71.

2 Студеникина Л.Н., Корчагин В.И., Шелкунова М.В., Дочкина Ю.Н. и др. Модификация полиэтилена микроцеллюлозой для повышения его иммобилизационной способности // Вестник ВГУ. 2018. № 3. С. 23-29.

3 Маркевич Р.М., Гребенчикова И.А., Роденко А.В., Вострова Р.Н. Особенности биоценоза активного ила, находящегося в свободном состоянии и иммобилизованного на полимерном носителе // Труды БГТУ. 2013. № 4. C. 219-223.

4 Давлетяров Р.Р., Бобыкин Д.В. Повышение надежности системы очистки сточных вод // Наука и технологии трубопроводного транспорта нефти и нефтепродуктов. 2013. № 2. С. 79-83.

5 Литти Ю.В., Некрасова В.К., Куликов Н.И., Симанькова М.В. и др. Обнаружение анаэробных процессов и микроорганизмов в иммобилизованном активном иле станции очистки сточных вод с интенсивной аэрацией // Микробиология. 2013. № 6. С. 672.
Представляют интерес дальнейшие исследования по модификации синтетической полиолефиновой матрицы функциональными наполнителями, в том числе из ряда полисахаридов, позволяющими повысить сродство материала-носителя с внеклеточным матриксом активного ила.

6 Ножевникова А.Н., Литти Ю.В., Куликов Н.И., Зубов М.Г. Новая технология очистки сточных вод с иммобилизацией активного микробного ила и эффективным удалением азота с участием анаммоксбактерий, реализованная на объектах зимней олимпиады Сочи-2014 г. // Биотехнология и качество жизни: Международная научно-практическая конференция. 2014. С. 410-411.

7 Нгуен Туан Ань, Кульков В.Н., Солопанов Е.Ю. Использование синтетических материалов на основе полиамидных волокон для интенсификации биологической очистки сточных вод// Известия вузов. Инвестиции. Строительство. Недвижимость. 2018. Т. 8. № 1. С. 168-174.

8 Долженко Л.А. Иммобилизация активного ила на носителях биореактора в условиях нитрификации и денитрификации // Образование и наука в современном мире. Инновации. 2016. № 4. С. 150-157.

9 Калашникова М.Е., Белик Е.С. Исследование способов адсорбционной иммобилизации углеводородокисляющих микроорганизмов на карбонизате // Экология и научно-технический прогресс. Урбанистика, 2013. T.1. C. $76-84$. 
10 Chernysh Y., Plyatsuk L. The carrier development for biofilms on the basis of technogenic wastes for pollutants treatment in the environmental protection technologies// Lecture Notes in Mechanical Engineering Volume. Part F2. 2019. P. 422-432.

11 Bidinger S.C., Dzedzig B. Mutag BioChip, the ultimate MBBR carrier for biological wastewater treatment. URL: http://www.mutag-biochip.com

12 Жердев В.Н., Студеникина Л.Н., Шелкунова М.В. Видовой состав активного ила из аэротенков ЛОС // Модели и технологии природообустройства (региональный аспект). 2016. № 1 (2). C. 34-39.

\section{REFERENCES}

1 Korchevska Y.V., Kudysheva A.A., Gorelkin G.A., Magagine A.A. et al. the Use of fluidized bed biological wastewater treatment. Vestnik Altajskogo gosudarstvennogo agrarnogo universiteta [Bulletin of Altai state agrarian University]. 2016. no. 2. pp. 67-71. (in Russian).

2 Studenikina L.N., Korchagin V.I., Shelkunova M.V., Dochkina Yu.N. et al. The Modification of polyethylene with microcellulose to increase its immobilization ability. Vestnik VGU [Vestnik VSU]. 2018. no. 3. pp. 23-29. (in Russian).

3 Markevich R.M., Grebenshikova I.A., Rodenko A.V., Vostrova R.N. Features of a biocenosis of active silt, in the free state and immobilized on the polymeric media. Trudy $B G T U$ [Proceedings of BSTU]. 2013. no. 4. pp. 219-223. (in Russian).

4 Davletyarov R.R., Bobykin D.V. improving the reliability of the wastewater treatment system. Nauka $i$ tekhnologii truboprovodnogo transporta nefti i nefteproduktov [Science and technology of pipeline transportation of oil and oil products]. 2013. no. 2. pp. 79-83. (in Russian).

5 Iitti Yu.V., Nekrasova V.K., Kulikov N.I., Simankova M.V. et al. Detection of anaerobic processes and microorganisms in immobilized activated sludge of wastewater treatment with intensive aeration. Mikrobiologiya [Microbiology]. 2013. no. 6. pp. 672. (in Russian).

\section{СВЕДЕНИЯ ОБ АВТОРАХ}

Любовь Н. Студеникина к.т.н., доцент, кафедра промышленной экологии, оборудования химических и нефтехимических производств, Воронежский государственный университет инженерных технологий, пр-т Революции, 19, г. Воронеж, 394036, Россия,lubov-churkina@yandex.ru

Юлия Н. Дочкина аспирант, кафедра промышленной экологии, оборудования химических и нефтехимических производств, Воронежский государственный университет инженерных технологий, пр-т Революции, 19, г. Воронеж, 394036, Россия, dochkina.j.n@yandex.ru

Мария В. Шелкунова аспирант, кафедра промышленной экологии, оборудования химических и нефтехимических производств, Воронежский государственный университет инженерных технологий, пр-т Революции, 19, г. Воронеж, 394036, Россия, mar.sher2010@yandex.ru

Владимир И. Корчагин д.т.н., зав. кафедрой, кафедра промышленной экологии, оборудования химических и нефтехимических производств, Воронежский государственный университет инженерных технологий, пр-т Революции, 19, г. Воронеж, 394036, Россия, kvi-vgta@rambler.ru

\section{КРИТЕРИЙ АВТОРСТВА}

Все авторы в равной степени принимали участие в написании рукописи и несут ответственность за плагиат

\section{КОНФЛИКТ ИНТЕРЕСОВ}

Авторы заявляют об отсутствии конфликта интересов.

ПОСТУПИЛА 10.09.2018

ПРИНЯТА В ПЕЧАТЬ 31.10 .2018
6 Nozhevnikova A.N., Iitti Yu.V., Kulikov N.I., Zubov M.G. New technology for wastewater treatment with immobilization of the active microbial sludge and an effective removal of nitrogen with the participation of anammoxbacteria implemented on the sites of the winter Olympic games Sochi-2014. Biotekhnologiya i kachestvo zhizni [Biotechnology and quality of life: International scientificpractical conference]. 2014. pp. 410-411. (in Russian).

7 Nguyen Tuan Anh, Kulkov V.N., Solopanov E.Yu. The use of synthetic materials based on polyamide fibers for intensification of biological purification of waste waters. Izvestiya vuzov. Investicii. Stroitel'stvo. Nedvizhimost' [Proceedings of the universities. Investment. Construction. Realty]. 2018. vol. 8. no. 1. pp. 168-174. (in Russian).

8 Dolzhenko L.A. Immobilization of activated sludge in the bioreactor media in the context of nitrification and denitrification. Obrazovanie i nauka v sovremennom mire. Innovacii [Education and science in the modern world. Innovations]. 2016. no. 4. pp. 150-157. (in Russian).

9 Kalashnikova M.E., Belik E.S. Investigation of methods of adsorption immobilization of hydrocarbonoxidizing microorganisms on carbonate. Ehkologiya i nauchno-tekhnicheskij progress. Urbanistika [Ecology and scientific and technical progress. Urbanism]. 2013. vol. 1. pp. 76-84. (in Russian).

10 Chernysh, Y., Plyatsuk, L. The carrier for biofilms development on the basis of technogenic wastes for pollutants treatment in the environmental protection technologies. Lecture Notes in Mechanical Engineering Volume. Part F2. 2019. pp. 422-432.

11 Bidinger S.C., Dzedzig B. Mutag BioChip, the ultimate MBBR carrier for biological wastewater treatment. Available at: http://www.mutag- biochip.com

12 Zherdev V.N., Studenikina L.N., Shelkunova M.V. Species composition of activated sludge from VOC aeration tanks. Modeli i tekhnologii prirodoobustrojstva (regional'nyj aspekt) [Models and technologies of nature management (regional aspect)]. 2016. no. 1 (2). pp. 34-39. (in Russian).

\section{INFORMATION ABOUT AUTHORS}

Lubov N. Studenikina Cand. Sci. (Engin.), associate professor, industrial ecology, chemical and petrochemical production equipment department, Voronezh state university of engineering technologies, Revolution Av., 19 Voronezh, 394036, Russia, lubov-churkina@yandex.ru

Julia N. Dochkina graduate student, industrial ecology, chemical and petrochemical production equipment department, Voronezh state university of engineering technologies, Revolution Av., 19 Voronezh, 394036, Russia, dochkina.j.n@yandex.ru

Mariya V. Shelkunova graduate student, industrial ecology, chemical and petrochemical production equipment department, Voronezh state university of engineering technologies, Revolution Av., 19 Voronezh, 394036, Russia, mar.sher2010@yandex.ru

Vladimir I. Korchagin Dr. Sci. (Engin.), head of department, industrial ecology, chemical and petrochemical production equipment department, Voronezh state university of engineering technologies, Revolution Av., 19 Voronezh, 394036, Russia, kvi-vgta@rambler.ru

\section{CONTRIBUTION}

All authors equally participated in the writing of the manuscript and are responsible for plagiarism

\section{CONFLICT OF INTEREST}

The authors declare no conflict of interest. RECEIVED 9.10.2018 ACCEPTED 10.31.2018 